8. We have prepared a considerable number of new compounds and we have devised improved methods for obtaining certain other substances.

The work will be continued in this laboratory during the coming academic year.

MCMaster UNIVERSITY.

TORONTO, CANADA.

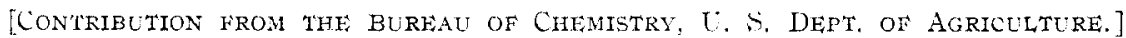

THE HYDROLYSIS OF SALICIN BY THE ENZYME EMULSIN.

\author{
By C. S. Hidson AND H. S. PAJNe. \\ Received September 20, rgog.
}

In aqueous solution salicin is hydrolyzed by strong acids to glucose and salicyl alcohol according to the equation,

$$
\mathrm{C}_{13} \mathrm{H}_{18} \mathrm{O}_{7}+\mathrm{H}_{2} \mathrm{O}=\mathrm{C}_{6} \mathrm{H}_{12} \mathrm{O}_{6}+\mathrm{C}_{7} \mathrm{H}_{8} \mathrm{O}_{2} \text {. }
$$

(Salicin) + (water) $=$ (glucose) + (salicyl alcohol.)

It has been found by $\mathrm{A}$. A. Noyes and $\mathrm{Hall}^{2}$ that the rate of this acid hydrolysis follows the law of unimolecular reactions. The same hydrolysis can also be accomplished by adding to the salicin solution a little of the enzyme of almonds, called emulsin, but in this case it has been stated by Henri ${ }^{3}$ and other investigators that the rate does not follow at all the unimolecular law. As this statement that the enzymotic hydrolysis of salicin by emulsin does not follow the usual laws of chemical dynamics has passed unchallenged for many years it has been widely accepted as correct. Against such a conclusion it is to be said that the glucose which is liberated from salicin by the action of emulsin is doubtless $\beta$-glucose because emulsin hydrolyzes only the $\beta$-glucosides, and $\beta$-glucose has a rotatory power of $20^{\circ}$, but Henri, in his work, assumed that the glucose had its usual specific rotation. $52^{\circ}$. His polariscopic measurements of the rate of the enzynotic hydrolysis are accordingly incorrect, for he made no correction for the mutarotation of glucose. In the hydrolysis by acids, as studied by $A$. A. Noyes and Hall, this second reaction, the mutarotation of slucose, does not affect the estimation of the extent of the hydrolysis from the polariscopic readings because the strong acid and the high temperature $\left(95^{\circ}\right)$ employed make the rate of the mutarotation instantaneous in comparison with the rate of the hydrolysis, but in the hydrolysis by emulsin the polariscopic readings do not give the real extent of the hydrolysis unless a considerable correction is made for the mutarotation of the freshly liberated glucose. The case is very similar to the hydrolysis of cane sugar by the enzyme invertase, in which reac-

\footnotetext{
+ Piria, Ann., 56, 37.

${ }^{2} Z$. physik. (hem., I8, 240-4 (I895).

${ }^{9}$ Lois générales de l'action des diastases, p. 102.
} 
tion the mutarotation of glucose has been shown by one of ss $^{1}$ to play an important part.

The Real and Apparent Courses of the Hydrolysis of Salicin by Emulsin. -The emulsin consisted of two samples, one from a chemical manufacturer who stated that it had been prepared from almonds, and a second which we prepared by digesting powdered bitter almonds for a day in water, filtering through cloth, precipitating a casein-like substance with a little acetic acid, filtering, and precipitating the emulsin with alcohol as a flocculent white mass. The salicin was prepared by recrystallizing a kilogram of commercial salicin once from alcohol and then twice from water. Five grams of this dry product dissolved in Ioo grams water gave a solution of specific gravity 1.013 at $30^{\circ}$, and of $-14.91^{\circ}$ rotation in a $50 \mathrm{~cm}$. tube; therefore the specific rotation of the pure salicin was -6 I.8. A. A. Noyes and Hal1 ${ }^{2}$ found -6 I. 5 to -62.2 and Tiemann ${ }^{3}$ -62.6. As it was expected that salicin on hydrolysis by emulsin would liberate $\beta$-glucose, which would slowly change partially to $\alpha$-glucose, means were taken to stop the action of the emulsin at definite instants by adding a little sodium carbonate; the slightly alkaline solution was then read in the polariscope. Special experiments proved that the action of the emulsin is stopped instantly by the sodium carbonate and that the mutarotation of the glucose reaches completion almost instantly in the alkaline solution; the rotation of these alkaline solutions therefore shows the real extent of the hydrolysis at the time the alkali was added. In the experiment reported in Table I, $500 \mathrm{cc}$. of an emulsin solution were mixed at the time $o$ with $20 \mathrm{~g}$. of finely powdered salicin, the solution filtered after one minute's shaking, and the filtrate kept at $30^{\circ}$ in a thermostat. A portion of it was used to fill a $50 \mathrm{~cm}$. jacketed observation tube which was also kept at $30^{\circ}$; the readings of this portion, as shown in column 2 of Table I and curve I of Fig. I, give the apparent course of the hydrolysis. It is this course which Henri measured. At intervals, portions of the main solution were made slightly alkaline with sodium carbonate and their rotations read; these readings give the real course of the hydrolysis and are shown in column 3 of Table I and curve 2 of Fig. I. The emulsin solution before the addition of the salicin had a rotation of -3.0 in a $50 \mathrm{~cm}$. length; as the addition of sodium carbonate to the emulsin in the absence of salicin did not change its rotation the latter was corrected for by the subtraction of -3.0 from all the readings. As thus corrected, the readings were all referred to -62.0 as the specific rotation of salicin for sodium light, the factor by which they were multiplied being $5 \cdot 17$.

${ }^{1}$ This Journal, 30, II60-6, I 564-83 (I908); 31, 655-64 (IgO9).

${ }^{2}$ Loc. cit.

${ }^{8}$ Ber., I8, 1600 (1885). 


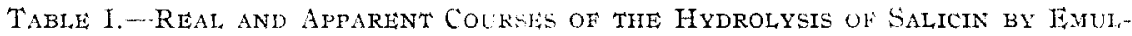
SIN. TEMPERATURE $30^{\circ}$.

Specific rotation.

$\begin{array}{ccc}\begin{array}{c}\text { Time }(t), \\ \text { minutes. }\end{array} & \begin{array}{c}\text { Neutral solution. } \\ \text { (Apparent course.) }\end{array} & \begin{array}{c}\text { Alkaline solution. } \\ \text { (Real course) }\end{array} \\ 01 & -62.0\left(R_{0}\right) & 62.0 \\ \text { In } & -17.0 & 8.6 \\ 20 & 11.3 & 23.7 \\ 30 & 13.7 & 25.6 \\ 40 & 19.4 & 27.6 \\ 30 & 22.5 & \ldots \\ 75 & 27.6 & \ldots .2 \\ 95 & 29.2 & 32.2 \\ \infty & 32.2(\mathrm{R})_{\infty} & \end{array}$

Velocity-coefficient $\mathrm{t}^{\mathrm{t}}\left(\mathrm{k}_{1}\right)$. Apparent course. Real course.
$0.0 \% 40.030$

0.01240 .035

6.0.2 2.020

$0.0120 \quad 0.026$

0.017

0.016

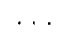

..

Average, 0.030

The data of Table I show that the usual polariscopic method of following the hydrolysis by reading the rotation of the neutral or slightly acid solution gives wholly incorrect results. The true extent of the hydrolysis

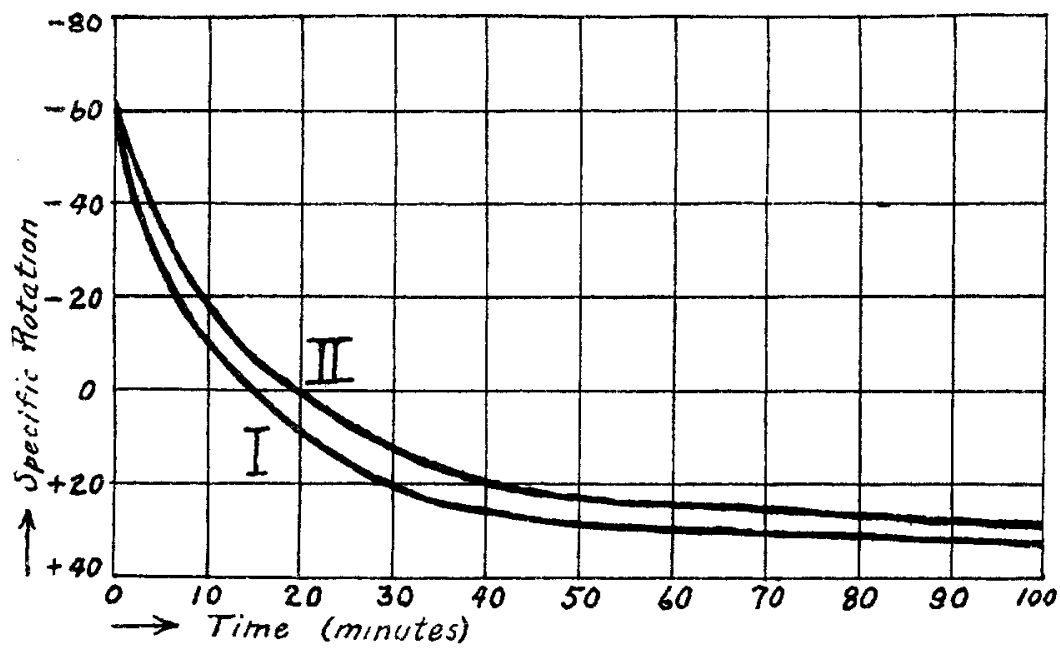

Fig. I.-Real (I) and apparent (II) courses of the hydrolysis of salicin by cmulsin.

can only be found when means are taken to correct for the mutarotation of the glucose. If the mutarotation is not corrected for, the apparent course of the hydrolysis is measured, and the data of column four show that this course does not follow the unimolecular law, since its

${ }^{1}$ Calculated by the usual formula, $k_{1}=\frac{r}{t} \log \frac{R_{0}-R_{\infty}}{R-R_{\infty}}$, the value of $R_{\infty}$ is calculated from the molecular weights and specific rotations of salicin and glucose, as other experiments whicl we have made show that the hydrolysis of salicin by emulsin is a complete one. 
velocity coefficient decreases regularly during the reaction. On the other hand, the data of column 5 show that the course of the real hydrolysis follows the unimolecular law, for its velocity coefficient shows no regular variation. These results largely explain why previous investigations, in particular those of Henri, have led to the conclusion that the hydrolysis of salicin by emulsin does not follow the unimolecular law, for Henri measured the apparent rate and obtained a regularly decreasing coefficient similar to ours, as shown in column 4 .

We have also measured the real rate of hydrolysis at $0^{\circ}$ and the results are reported in Table II. The concentration of the salicin was 3.5 per cent. The first reading was taken one hour after mixing the salicin and emulsin because the temperature was somewhat above zero during this hour; this reading is accordingly lower than -62.0 , the specific rotation of salicin.

Table II.-Real Course of the Hydrolysis of Salicin by Emulsin. TemperaTURE $0^{\circ}$.

\begin{tabular}{|c|c|c|}
\hline Time $(t)$, hours. & $\begin{array}{l}\text { Specific rotation, alkaline solution. } \\
\text { (Real course.) }\end{array}$ & Velocity-coefficient $\left(k_{1}\right)$. \\
\hline 0 & $-37 \cdot 5$ & $\ldots$ \\
\hline $\mathbf{I}$ & -13.8 & 0.073 \\
\hline 2 & $-17 . \mathrm{r}$ & 0.075 \\
\hline 3 & $-I I \cdot 3$ & 0.068 \\
\hline 5 & $\rightarrow 2.4$ & 0.073 \\
\hline 7.5 & 9.6 & 0.065 \\
\hline \multirow{3}{*}{$\begin{array}{l}9.5 \\
\infty\end{array}$} & I 5.6 & 0.066 \\
\hline & 32.2 & $\ldots$ \\
\hline & & verage, \\
\hline
\end{tabular}

This experiment shows a satisfactory constancy for the value of $k_{1}$, proving that the enzymotic hydrolysis follows the unimolecular law.

Table III.-Real Course of the Hydrolysis of Salicin by Emulsin. TemperaTURE $30^{\circ}$.

Time $(t)$, minutes.

0
10
20
30
35
85
145

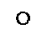

Io

20

30

35

I 45

$\infty$
Specific rotation, alkaline solution.

$$
\text { (Rea1 course.) }
$$

$-62.0$

$-54.5$

$-48.7$

-4 I. 6

$-39.5$

$-15.8$

$+2.9$

$+32.2$
Velocity-coefficient $\left(k_{1}\right)$.
0.00360
0.00330
0.00353
0.00339
0.00344
0.00350
...

Average, 0.00346

This experiment also shows a satisfactory constancy for $k_{1}$.

The real rate of hydrolysis was also measured at $30^{\circ}$ in a third experiment, as shown in Table III. The salicin solution was of 5 per cent. 
strength. In this experiment the action of the emulsin was stopped by quickly heating portions of the solution, a procedure which aiso brings the mutarotation to completion; it has the adrantage orer the addition of sodium carbonate in that the red color which the latter forms with salicyl alcohol is not produced in such intensity and the polariscopic view is accordingly clearer.

The Fom of Giucose which is I thrated from salicin by the Action of Fimulsin.-.- From the fact that the addition of alkali to the salicin solutions which are undergoing hydrolysis causes an increase of dextrorotation, it may be concluded that the glucose which is liberated from the saliciti is less dextrorotatory than $52^{\circ}$, the rotation of stable or alkaline solutions of glucose. Only one form of glucose is known which has such lower rotation. namely, 3 -glucose, of specific rotation $20^{\circ}$. That this is incleed the form which is liberated from salicin nay be accurately shown as follows: $:^{1}$ Start with i molecules of salicin in unit rolume of solution at constant temperature and let there be present at the time $t$, w molecules of fresh glucose and $y$ molecules of stable glucose. The rates of formation at the time $t$ are:

(1) For fresh glucose, $d w / d t=k_{1}(A-w-y)-k_{2} w$,

(2) For stable glucose, $d y / d t=k_{2} w$.

In these experiments $k_{1}$ is the velocity coefficient of the real rate of hydrolysis, and $k_{2}$ is the velocity coefficient of the mutarotation of glucose. The solution of these equations under the conditions which obtain (that at the time zero, $w, y$, and $d y / d t$ are all zero) is

$$
\begin{gathered}
w=A \frac{k_{1}}{k_{2}-k_{1}}\left[e^{-k_{1} t}-e^{-k_{2} t}\right], \\
y=A\left[\mathrm{I}+\frac{k_{1}}{k_{2}-k_{1}} e^{-k_{2} t}-\frac{k_{2}}{k_{2}-k_{1}} e^{-k_{1} t}\right] .
\end{gathered}
$$

In the experiment reported in Table I, the coefficient $k_{1}$ has the value 0.030 , using decimal logarithms. At the temperature of this experiment $\left(30^{\circ}\right)$, it was found in a previous investigation ${ }^{2}$ that the velocity coefficient of the mutarotation of glucose, $k_{2}$, has the value 0.017 , and the presence of salicin and emulsin in the solution has no effect on $k_{2}$. Substituting the values 0.030 and 0.017 for $k_{1}$ and $k_{2}$, respectively, in equation (3) the relative number of gram-molecules of fresh glucose, $w / A$, which were present in the solution of Table I at the different instants when the polariscopic readings were made have been calculated and are given in column 3 of Table IV. In column 2 are the changes of rotation caused by the addition of the sodium carbonate, obtained by

1 This mathematical treatment is closely analogous to that previously used in studying the inversion of cane sugar by invertase. THrs Jourval, 30, 1576 (Ig08).

${ }^{2}$ This Journal, 30, 1577 (1908). 
subtracting in Table I, column 3 from column 2. The last column of Table IV gives the specific rotation of the fresh glucose as calculated Table IV.-Calculated Specific Rotation of Fresh Glucose from Salicin.

Time
0
20
30
40
50
$\infty$

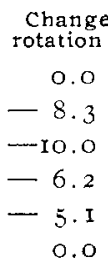

Fresh glucose.
$(w / A)=\mathrm{W}$.

0.00

0.48

o. 42

o. 34

0.25

0.00
Calc. specific totation of fresh glucose.

$\begin{array}{rrr}0 & 0.0 & 0.00 \\ 20 & -8.3 & 0.48 \\ 30 & -10.0 & 0.42 \\ 40 & -6.2 & 0.34 \\ 50 & -5.1 & 0.25 \\ \infty & 0.0 & 0.00\end{array}$

$25^{\circ}$
$15^{\circ}$
$23^{\circ}$
$20^{\circ}$
$\ldots$

Average, 2 I

from the data of columns 2 and 3 by the formula which has been given in a former article $;^{1}$ specific rotation $=52.5+\frac{286 \mathrm{D}}{\mathrm{I} 80 \mathrm{~W}}$, where 52.5 is the specific rotation of stable glucose, 286 the molecular weight of salicin, I 80 that of glucose, $D$ the change of rotation of column two, and $W$ the per cent. of fresh giucose in gram-molecules from column 3 . The average value is $2 \mathrm{I}^{\circ}$ and as the specific rotation of $\beta$-glucose has been found by $\operatorname{Roux}^{2}$ to be $20^{\circ}$, and that of $\alpha$-glucose $\mathrm{IIO}^{\circ}$, the agreement proves that the form of glucose which is liberated from salicin by the enzymotic action of emulsin is $\beta$-glucose.

The Infuence of Acids and Alkalis on the Actizity of Emulsin.-The enzyme emulsin is very sensitive to acids and alkalis. In Table $V$ are recorded a series of measurements of the rate at which a constant quantity of emulsin hydrolyzed at $35^{\circ}$ a four per cent. salicin solution containing different amounts of hydrochloric acid or sodium hydroxide. The results are shown also in Fig. 2.

Table V.-Activity of Emulsin towards Salicin in Acid and Alkaline SoluTIONS.

\begin{tabular}{|c|c|c|c|c|c|}
\hline $\begin{array}{l}\text { Experiment } \\
\text { number. }\end{array}$ & $\begin{array}{l}\text { Concentra- } \\
\text { tion NaOH } \\
\text { mols/liter. }\end{array}$ & $\begin{array}{c}\text { Activity }{ }^{3} \\
\text { of emulsin. }\end{array}$ & $\begin{array}{l}\text { Experiment } \\
\text { number. }\end{array}$ & $\begin{array}{l}\text { Concentra. } \\
\text { tion HCl } \\
\text { mols/litet. }\end{array}$ & $\begin{array}{l}\text { Activity } \\
\text { of emulsin. }\end{array}$ \\
\hline I & 0.009 & 0 & 7 & 0.00009 & 222 \\
\hline 2 & 0.005 & 0 & 8 & 0.00027 & 222 \\
\hline 3 & 0.0009 & 138 & 9 & 0.0005 & 225 \\
\hline 4 & 0.0005 & I95 & IO & 0.0018 & 242 \\
\hline 5 & 0.00009 & 215 & II & 0.005 & 255 \\
\hline \multirow[t]{4}{*}{6} & Distilled water & 222 & I 2 & 0.009 & 206 \\
\hline & & & I 3 & O.OII & 77 \\
\hline & & & I4 & 0.014 & 0 \\
\hline & & & I 5 & 0.040 & o \\
\hline $\begin{array}{l}{ }^{1} \text { This Jo } \\
2 \text { Ann. ch } \\
{ }^{3} \text { The val }\end{array}$ & $\begin{array}{l}\text { RNAL, } 30, \text { I } 58 \text { I (I) } \\
m \text {. phys. }[7], 30,42 \\
\text { les of the activity }\end{array}$ & $\begin{array}{l}\text { I } 908) . \\
422(1903) . \\
y \text { are those }\end{array}$ & of the veloci & coefficient & the hydroly \\
\hline
\end{tabular}


Emulsin is entirely inactive towards salicin except in the region just about neutrality. In this respect it resembles the enzyme invertase, but the range of activity of emulsin does not extend into as strong acidity as does that of invertase, and extends farther into alkalinity. The

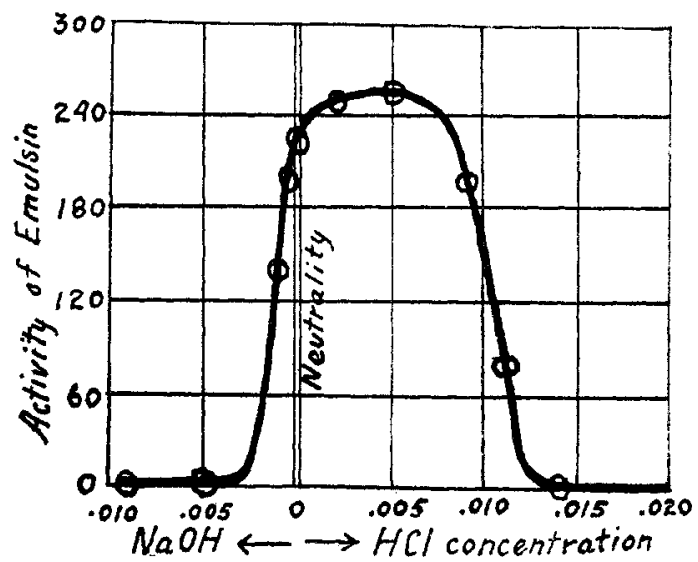

Fig. 2.-Influence of acidity and alkalinity on the activity of emulsin. emulsin solution which was used in the above experiments was dialyzed several days in order to remove as much as possible any salts, acids, or alkalis that may have originally been in the infusion of almonds; the dialyzed solutions were neutral to litmus. Since the curve of activity (Fig, 2) is not very stee $p$ at the point of neutrality, there is no need for making the emulsin solutions slightly acid in order to obtain steady and reproducible conditions for the hydrolysis. This is in strong con1trast to the enzyme invertase, for which the curve is exceedingly steep near neutrality and the addition of acid to bring the rate into a region where the slope is less steep, quite important.

Summary.-The conclusions of our investigation, which had for its purpose the development of an accurate polariscopic method for measuring the activity of the enzyme emulsin, may be summarized as follows: The glucose which is produced from salicin by the action of emulsin is shown to have the rotation $15^{\circ}-25^{\circ}$, agreeing with the known rotation of $\beta$-glu$\operatorname{cose}, 20^{\circ}$, and differing entirely from that of $\alpha$-glucose, $110^{\circ}$. The glucose from salicin is therefore $\beta$-glucose. A secondary reaction, the mutarotation of glucose, affects the polariscopic readings of the salicin solutions during the hydrolysis by emulsin and is a chief source of error in the measurements of Henri, who found that the hydrolysis does not follow the unimolecular order. No such error is present in the measurements of the hydrolysis of salicin by acids, studied by A. A. Noyes and Hall, because the strong acid and the high temperature $\left(95^{\circ}\right)$ which were employed made the rate of mutarotation instantaneous in comparison with the rate of the hydrolysis; they found that the rate of the acid hydrolysis follows the unimolecular order. We have measured the real rate of the hydrolysis of salicin by emulsin at $0^{\circ}$ and $30^{\circ}$ by making the solution slightly alkaline before reading it in the polariscope, and this rate we found to follow the unimolecular order. Emulsin is active in 
only a small region of acidity and alkalinity near the neutral point, as shown in Fig. 2. We expect to apply the above accurate polariscopic method in a further study of the hydrolysis of salicin and other substances by emulsin, in order to learn the laws of the action of this enzyme.

[From the Laboratory of Phystological Chemistry, Department of Animal

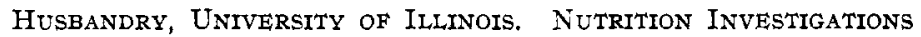
Publication No. 27.]

\section{TOTAL NITROGEN DETERMINATION BY THE KOBER METHOD.}

BX F. W. GILL AND H. S. GRINDLEY.

Received September 6, 1909

In ThIS JournaL ${ }^{1}$ Kober describes a new method for the quantitative estimation of ammonia as obtained in the total nitrogen determination of organic substances. Since this method of aeration has certain advantages in that it requires practically no attention when once started and uses no heat for distillation, we undertook a detailed study of the method in the hope of its adoption in this laboratory.

The very excellent results that we have obtained by the aeration process for urea in urine, ${ }^{2}$ and for ammonia in urine, by the Folin ${ }^{3}$ process also influenced us to investigate this method of Kober's for the total nitrogen in organic materials. The Kober method in substance is as follows: After the usual digestion of the organic material in the Kjeldahl flasks with $25 \mathrm{cc}$. of concentrated chemically pure sulphuric acid, mercury, and potassium sulphate, the liquids are cooled and from 90 to $95 \mathrm{cc}$. of ammonia-free distilled water is then added to each of the Kjeldahl flasks. The diluted acid solutions thus formed are cooled to room temperature. The Kjeldahl flasks are connected to I6-ounce bottles, each of which contains a measured excess of standard sulphuric acid plus I $30 \mathrm{cc}$. of ammonia-free water for the ammonia absorption. The Kjeldahl flasks are also connected to vessels, from which is drawn through a widened tube, by the air current, the necessary amount of caustic-soda-sodium-sulphide solution.

After the alkaline solution has been drawn into the Kjeldahl flasks, wash bottles containing the dilute sulphuric acid for rendering the air for aeration ammonia-free, are attached in place of the vessels which contained the caustic alkali solution. The rapid, but not violent, aeration of the solutions in the Kjeldahl flasks is continued for at least one and one-half hours.

We have applied this modification of Kober's to the determination of

${ }^{1} 30,1131$ (1908).

2 THIS JOURNAL, 3 I, IO89 (I9O9).

${ }^{3} Z$. physiol. Chem., 37, 161 (1902) 